\title{
AS FASES DE OCUPAÇÃO E IMPLANTAÇÃO DO CEMITÉRIO SÃO JOÃO BATISTA, MUNICÍPIO DE PRESIDENTE PRUDENTE - SP
}

\author{
Letícia Aparecida Costa ${ }^{1}$ \\ Bruno Magro Rodrigues ${ }^{2}$ \\ Marcos Norberto Boin ${ }^{3}$
}

\begin{abstract}
RESUMO
Essa pesquisa teve como objetivo de analisar as fases de ocupação e implantação do cemitério Municipal São João Batista, levando em consideração as características físicas da área do cemitério, verificando as implicações na forma que a área foi ocupada, tanto temporal, quanto espacialmente e, principalmente suas implicações sobre os recursos hídricos. Tendo em vista o potencial de contaminação dos cemitérios e a capacidade de alterações dos meios físico e biótico, esta atividade confere um alto impacto ambiental. Perante a problemática exposta, se torna indispensável identificar quais impactos ocasionados pela implantação e operação do cemitério São João Batista no município de Presidente Prudente - SP, buscando contribuir para a minimização destas alterações antrópicas. O cemitério em estudo está localizado no município de Presidente Prudente - SP, em área urbana, ocupando uma área de aproximadamente $182.000 \mathrm{~m}^{2}$. Para a elaboração do trabalho realizou-se levantamento bibliográfico sobre conceitos relacionados ao meio ambiente, contaminação em cemitérios, poluição das águas e solo, decomposição pela decomposição de cadáveres, poluição ambiental, e geotecnologias. Durante muitos anos uma extensa porção do cemitério foi destinada para o sepultamento realizado diretamente no solo, o que impactou sobremaneira essa área, sendo que apenas no ano de 2001 essa prática foi extinta. A ampliação do cemitério ocorreu sem planejamento, acontecendo em áreas inadequadas e facilitando que o necrochorume penetrasse no solo. É de extrema importância planejar os cemitérios, pois os sepultamentos acontecem de forma permanece, e os corpos precisam passar pelo processo de decomposição afetando o mínimo possível os recursos naturais.
\end{abstract}

PALAVRAS-CHAVE: Impacto Ambiental. Planejamento. Recursos Hídricos.

\section{PHASES OF OCCUPATION AND IMPLEMENTATION OF THE CEMETERY SAINT JOHN BAPTIST , PRESIDENTE PRUDENTE - SP}

\footnotetext{
${ }^{1}$ Mestranda em Meio Ambiente e Desenvolvimento Regional, Universidade do Oeste Paulista. lecosta.amb@gmail.com.

${ }^{2}$ Mestrando em Meio Ambiente e Desenvolvimento Regional, Universidade do Oeste Paulista. b_magro@hotmail.com.

${ }^{3}$ Doutor em Geociências. boinmar@hotmail.com
} 


\begin{abstract}
This study aimed to analyze the phases of occupation and implementation of the Municipal Cemetery São João Batista, taking into account the physical characteristics of the area of the cemetery, checking the implications for the way that the area was occupied, both temporal and spatially, and especially its implications on water resources. Given the potential for contamination of cemeteries and the ability to change the physical and biotic means, this activity provides a high environmental impact. In view of the problems exposed, it becomes essential to identify which impacts caused by the implementation and operation of São João Batista cemetery in the municipality of Presidente Prudente - SP, aiming to contribute to the minimization of these anthropogenic changes. The cemetery under study is located in the municipality of Presidente Prudente - SP, in urban areas, covering an area of approximately $182,000 \mathrm{~m}^{2}$. For the preparation of the work took place literature on concepts related to the environment, contamination in cemeteries, water pollution and soil decomposition by the decomposition of corpses, environmental pollution, and geotechnology. For many years a large portion of the cemetery was destined for burial performed directly in the soil, which greatly impacted this area, and only in 2001 this practice was abolished. The expansion of the cemetery took place without planning, happening in unsuitable areas and facilitating the necrochorume penetrate the soil. It is extremely important to plan the cemeteries, because the burials happen so remains, and the bodies need to go through the decomposition process affecting as little as possible the natural resources.
\end{abstract}

KEYWORDS: Environmental Impact. Planning. Water Resources.

\title{
FASES DE OCUPACIÓN Y APLICACIÓN DEL CEMENTERIO SAN JUAN BAUTISTA PRESIDENTE PRUDENTE - SP
}

\section{RESUMEN}

Este estudio tuvo como objetivo analizar las fases de ocupación y la aplicación del Cementerio Municipal de San Juan Bautista, teniendo en cuenta las características físicas de la zona del cementerio, revisando las implicaciones para la forma en que la zona fue ocupada, tanto temporal como espacialmente, y especialmente sus implicaciones sobre los recursos hídricos. Dado el potencial de contaminación de los cementerios y la capacidad de cambiar los medios físicos y bióticos, esta actividad proporciona un alto impacto ambiental. En vista de los problemas expuestos, es esencial para identificar que los impactos causados por la implementación y operación de São João Batista cementerio en el municipio de Presidente Prudente - SP, con el objetivo de contribuir a la minimización de estos cambios antropogénicos. El cementerio en estudio se encuentra en el municipio de Presidente Prudente - SP, en las zonas urbanas, con una superficie de aproximadamente $182.000 \mathrm{~m}^{2}$. Para la preparación de la obra se llevó a cabo la literatura sobre los conceptos relacionados con el medio ambiente, la contaminación en los cementerios, la contaminación del agua y la descomposición del suelo por la descomposición de los cadáveres, la contaminación ambiental y geotécnica. Durante muchos años una gran parte del cementerio estaba destinado para el entierro efectuada directamente en el suelo, lo que afectó en gran medida esta área, y sólo en 2001 se abolió esta práctica. La ampliación del cementerio se llevó a cabo sin planificación, pasando en zonas no aptas y facilitar la necrochorume penetrar en el suelo. Es muy importante planificar los cementerios, porque los entierros ocurren por lo que queda, y los cuerpos tienen que pasar por el proceso de descomposición que afecta lo menos posible los recursos naturales.

PALABRAS CLAVE: Impacto Ambiental. Planificación. Recursos Hídricos. 


\section{INTRODUÇÃO}

A morte não é encarada de modo aprazível, é vista com olhares malévolos e nunca bem recebida, para se the fugir, é feito o possível e o impossível. Nesse sentido, o cemitério, lugar onde descansam os defuntos, é o reino tenebroso da morte, onde a população depara com um fortíssimo estoque de assombrações e medo (PACHECO, 2012).

Pacheco (2012) discorre que, a morte, em derradeiro diagnóstico, é um acontecimento ecológico, um desfecho natural e necessário do ciclo da vida, inflexível para todos os seres que respiram e até mesmo os anaeróbios. Mas mesmo assim, a decomposição do corpo é uma considerável fonte de impacto ambiental.

Um dos principais causadores da contaminação em cemitérios é o necrochorume, que segundo a Companhia Ambiental do Estado de São PauloCETESB (1999, p. 2) é:

O líquido resultante da decomposição de cadáveres. Trata-se de uma solução aquosa rica em sais minerais e substâncias orgânicas desagradáveis, de cor castanho-acinzentada, mais viscosa que a água, polimerizável, de odor forte e pronunciado, com grau variado de toxicidade e patogenicidade.

Devido à necessidade de denominar o resíduo líquido que resulta do processo de decomposição dos cadáveres, o termo necrochorume foi criado pelos técnicos da CETESB, que também é conhecido por líquidos humorosos (MIOTTO, 1990).

Essa palavra surgiu pelo neologismo do termo "chorume", que é o líquido que resulta da decomposição da matéria orgânica presente nos lixos domésticos. Quando a decomposição dos corpos se inicia, o necrochorume, que é a dissolução do cadáver, origina a fase chamada de período coliquativo ou humoroso. É nessa fase que a matéria orgânica se liquefaz, e esse líquido pode atingir até 10 litros por cadáver (MIOTTO, 1990).

Segundo Miotto (1990, p. 74) "A contaminação pela dissolução dos cadáveres, na qual existem substâncias tóxicas como a cadaverina e a putrescina, pode-se dar no solo, nas águas superficiais e subterrâneas".

De acordo com Pacheco (2012), os cemitérios, como laboratório de decomposição de corpos, também contaminam o ambiente, em especial a água subterrânea, por coliformes fecais e microrganismos patogênicos, como bactérias e vírus. Assim sendo, medidas de prevenção devem ser tomadas na implantação de 
necrópoles, levando também em consideração a distância destas em relação aos mananciais de superfície e aos poços de captação de água subterrânea.

As águas que acabam sendo contaminadas por microrganismos provenientes da decomposição de cadáveres sepultados em cemitérios são um grande problema de saúde pública (PACHECO, 2012). Geralmente estão localizados nos centros urbanizados, possuindo um relacionamento intrínseco com o meio.

Os líquidos resultantes do processo de decomposição de cadáveres nos cemitérios se caracterizam pela alta concentração de microrganismos, muitos dos quais patógenos, que colocam em risco os recursos hídricos subterrâneos. Por isso a necessidade de se ter um local adequado ao corpo humano após a morte, principalmente por questões sanitárias e ambientais. (PACHECO, 2012).

A World Health Organization - WHO (1998) se mostra preocupada com os impactos que os cemitérios podem causar ao meio ambiente, através do aumento da concentração de substâncias orgânicas e inorgânicas nas águas subterrâneas e eventual presença de microrganismos patogênicos.

De acordo com Ottoman (1987), os cemitérios por serem fontes de contaminação ambiental, devem ter a sua localização e operação adequadas, pois a instalação incorreta de necrópoles em meios urbanos pode provocar a contaminação de mananciais hídricos por microrganismos que proliferam no processo de decomposição dos corpos. Se o aquífero freático for contaminado na área interna do cemitério, esta contaminação poderá fluir para regiões próximas, aumentando o risco de saúde nas pessoas que venham a utilizar desta água captada através de poços.

Devido à composição química do necrochorume, encontram-se números elevados de bactérias degradadoras de matéria orgânica (bactérias heterotróficas), de proteínas (bactérias proteolíticas) e lipídios (bactérias lipolíticas). Devem-se encontrar bactérias que são normalmente excretadas por humanos (e animais), como Escherichia coli, Enterobacter, Klebsiella e Citrobacter (as quatro formam o grupo coliforme total), Streptococcus faecalis; alguns clostrídios como Clostridium perfringes e Clostrídeum welchii, entre outros. É provável que estejam presentes bactérias patogênicos, como Salmonela typhi e vírus humanos, como enterovírus. 
Biólogos são de opinião que o perigo do necrochorume está na sua patogenicidade (OTTOMAN, 1987).

Porto (2012) sugere que um dos grandes desafios em que a sociedade atual enfrenta é na gestão da qualidade ambiental, buscando o equilíbrio entre as atividades que geram o desenvolvimento econômico e a preservação, ou conservação do meio ambiente. Esse propósito de desenvolvimento sustentável sugere que a geração atual supra suas necessidades, mas sem comprometer as necessidades das futuras gerações.

O uso e a ocupação do solo em áreas urbanas e rurais são os principais impactos que interferem na qualidade das águas, pois intensificam a remoção da vegetação, a erosão, a impermeabilização do solo e a produção de carga difusa de esgoto doméstico e industrial, causando o assoreamento dos rios, a deterioração da qualidade das águas, provocam alterações estéticas, desequilíbrio ecológico, aumento das inundações e de doenças de veiculação hídrica, etc. (PORTO, 2012).

A poluição tem um sentido amplo, não se restringe apenas quando ocorrem doenças no homem, mas qualquer alteração de um ambiente, sendo ele ar, água ou solo, que resulte em danos aos organismos vivos, é considerada poluição (MOTA, 2010). Portanto, os cemitérios são fontes de poluição e possíveis contaminações. A poluição se dá pela alteração das condições naturais que existiam ali, e a contaminação pode ocorrer devido ao contato do meio natural com componentes xenobióticos.

É evidente que os cemitérios adequadamente projetados e inseridos no meio ambiente, e operados seguindo regras sanitárias e higiênicas em vigor, apresentam uma relação de moderação e de sustentabilidade com o meio. Porém, percebe-se que grande parte desses empreendimentos foram construídos sem grandes preocupações com o meio ambiente (PACHECO, 2012).

Tendo em vista o potencial de contaminação dos cemitérios e a capacidade de alteração dos meios físico e biótico, confere a esta atividade um alto impacto ambiental.

Perante a problemática exposta, tornou-se indispensável apontar os impactos ocasionados pela implantação e operação do cemitério São João Batista no município de Presidente Prudente - SP, onde buscou contribuir para a 
minimização destas alterações antrópicas que muitas vezes são de amplitude desconhecida.

\section{OBJETIVOS}

\subsection{OBJETIVOS GERAIS}

Analisar as fases de ocupação e implantação do cemitério Municipal São João Batista, no município de Presidente Prudente-SP.

\subsection{OBJETIVOS ESPECÍFICOS}

- Levantar as características físicas da gleba do cemitério São João Batista, verificando suas implicações na forma de ocupação da área.

- Avaliar a forma de ocupação temporal e espacial do Cemitério São João Batista, em especial as suas consequências sobre os recursos hídricos.

\section{METODOLOGIA}

O cemitério em estudo está localizado no município de Presidente Prudente - SP, em área urbana, na Rua José Bongiovani, o 975, Vila Liberdade, ocupando uma área de aproximadamente $182.000 \mathrm{~m}^{2}$. Pondera-se que a atividade teve início na década de 1960. O município de Presidente Prudente está localizado no oeste do Estado de São Paulo, com uma população estimada do IBGE (2014) de 220.599 mil habitantes.

O cemitério São João Batista está exemplificado na Figura 1, por meio de imagem aérea. 
figura 1- Imagem Aérea do cemitério São João Batista.

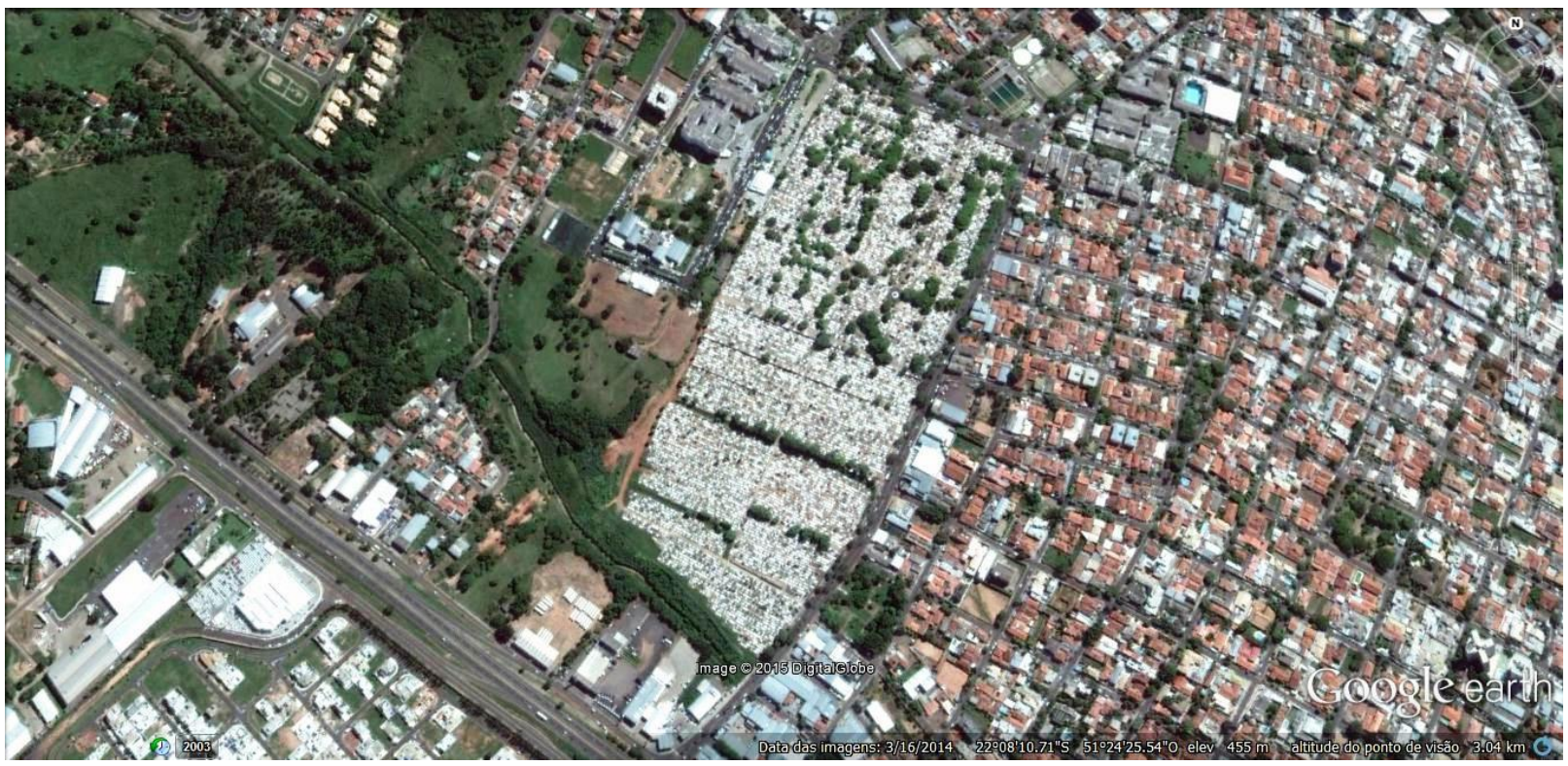

Fonte: GOOGLE EARTH, 2014.

Para a elaboração do trabalho realizou-se levantamento bibliográfico sobre conceitos relacionados ao meio ambiente, contaminação dos cemitérios, poluição das águas e solo, decomposição de cadáveres, poluição ambiental, e geotecnologias.

Empregando técnicas de geoprocessamento e sensoriamento remoto, por meio do Programa Spring 5.2.3, sobre imagem de fotografias aéreas e satélite do Google Earth, mapeou-se a área do cemitério São João Batista, levantando historicamente as fases de implantação e ocupação, nos últimos 47 anos (1967 a 2014), e o software Corel Draw X6 onde realizou-se o tratamento final das imagens.

Estas informações permitiram uma análise temporal e espacial da ocupação da área do cemitério e uma avalição de suas implicações na possível contaminação dos recursos hídricos subterrâneos.

Para o desenvolvimento deste procedimento de análise espacial, foram utilizadas imagens do Google Earth, que depois de obtidas foram georeferenciadas no programa Spring, para compor o banco de dados da área em questão.

Foram realizados trabalhos de campo no interior do cemitério São João Batista, para compreender a evolução da ocupação do mesmo, e verificar a atual situação. 


\section{RESULTADOS}

Visto a necessidade ambiental de preservação do solo e dos recursos hídricos superficiais e subterrâneos, se torna de extrema importância normas técnicas para a implantação de empreendimentos com potencialidade poluidora, como a Resolução CONAMA 335/2003 que dispõe sobre o licenciamento ambiental dos cemitérios e a Resolução CONAMA 396/2008 que dispõe sobre a classificação e diretrizes ambientais para o enquadramento das águas subterrâneas. Os cemitérios estão intrinsicamente relacionados com a saúde pública e à qualidade ambiental (CETESB, 1999).

Por meio da Figura 2 e 3, pode-se perceber a evolução da ocupação no São João Batista.

Figura 2 - Evolução do Cemitério entre 1967 e 2007.

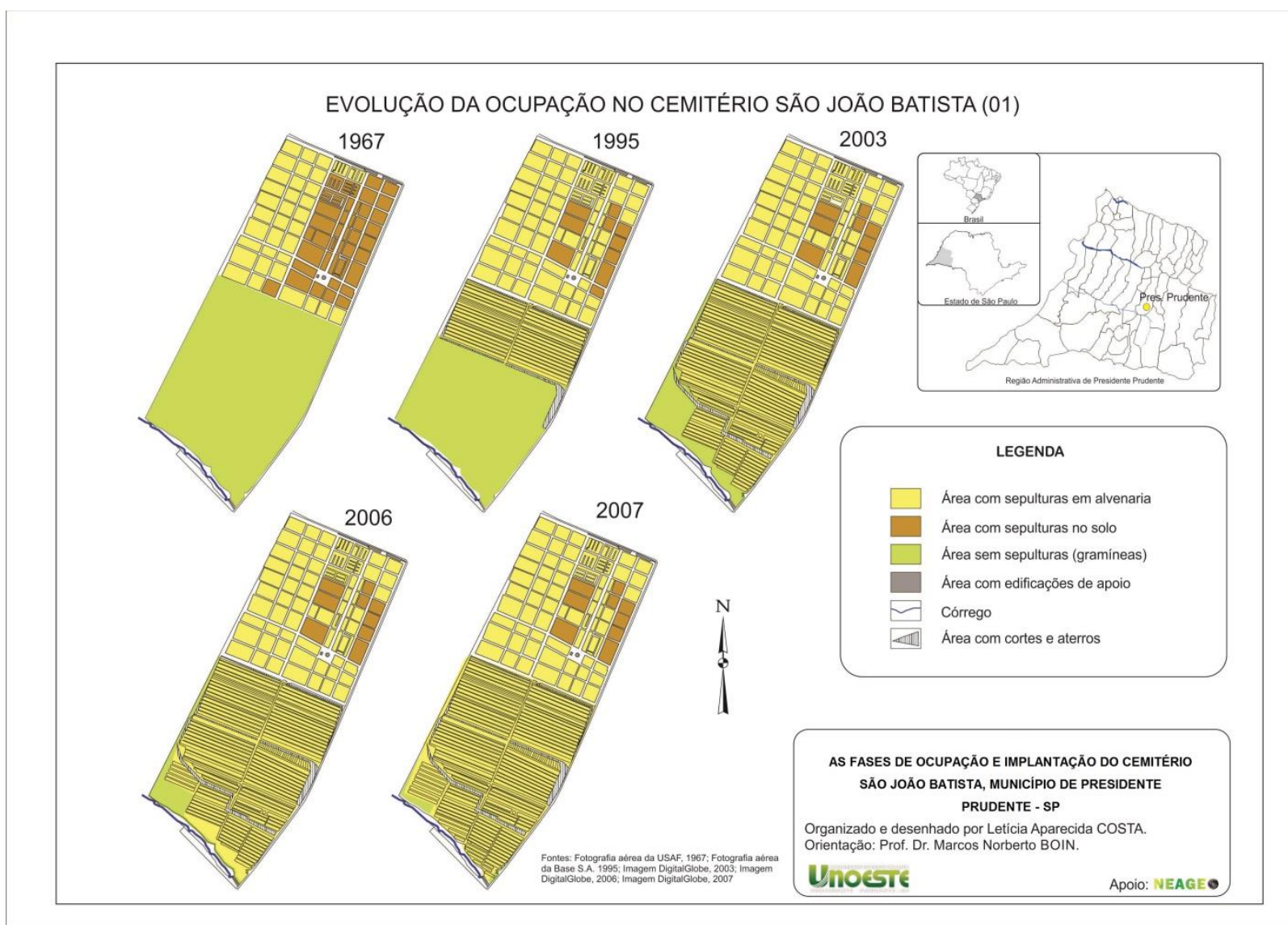

Fonte: Costa, 2014.

Com as figuras da evolução da ocupação da área, nota-se que em 1967 uma grande área era destinada para o sepultamento diretamente no solo, sem 
qualquer tipo de isolamento do corpo, a não ser o caixão, o que ocasionou uma elevada contaminação dessa área, pois proporciona uma facilidade do necrochorume (proveniente da decomposição dos corpos) infiltrar no solo e águas subterrâneas, além de ser uma área com elevada rotatividade de cadáveres, influenciando sobremaneira na quantidade de necrochorume produzido.

É possível observar que uma área extensa já era destinada aos sepultamentos, visto que o cemitério antigo da cidade localizado na Avenida Brasil atual rodoviária foi desativado e os restos mortais foram levados para o cemitério São João Batista. Destaca-se que os corpos vindos da Av. Brasil, de acordo com normas existentes, foram exumados após a dissolução pútrida das partes moles do corpo, o que pode ter minimizado a contaminação desta área mais antiga.

A partir no ano de 1995, essa área destinada aos sepultamentos diretamente no solo começaram a diminuir e também ocorreu à necessidade de ampliação do cemitério e para tal começou a ser realizado o acréscimo em direção ao córrego Ferreirinha, localizado na parte inferior do cemitério. Paralelo a ampliação iniciada no ano de 1995, houve a redução da área destinada para o sepultamento diretamente no solo e se iniciou a construção de cortes e aterros para regularizar e adequar a topografia à construção dos jazigos. Nos anos de 2006 e 2007 a situação não se alterou com relação às intervenções sobre as vertentes, mas acabou por avançar sobre as áreas de preservação permanente ao longo do córrego Ferreirinha, nitidamente visto no ano de 2007.

Essa ampliação do cemitério não levou em consideração os aspectos geológicos, geomorfológicos, e hidrológicos da área em questão, pois esses aspectos são muito relevantes para gerir um cemitério. Devido esse descaso com as características naturais da área, acaba ocasionando um elevado impacto ambiental.

De acordo com a Resolução CONAMA ㄲo 001 de 1986 em seu artigo 1ํำ define que impacto ambiental é:

Qualquer alteração das propriedades físicas, químicas e biológicas do meio
ambiente, causada por qualquer forma de matéria ou energia resultante das
atividades humanas que, direta ou indiretamente, afetem: (I) a saúde, a
segurança e o bem-estar da população; (II) as atividades sociais e
econômicas; (III) a biota; (IV) as condições estéticas e sanitárias do meio
ambiente; (V) a qualidade dos recursos ambientais.

Os impactos negligenciados no cemitério São João Batista foram principalmente referente as características do relevo, pois a geomorfologia da área 
não é indicada para esse empreendimento, que necessita escavar a área, aproximando os contaminantes da decomposição dos corpos do lençol freático.

$\mathrm{Na}$ Figura 3, pode-se continuar a observar a evolução da ampliação do cemitério.

Figura 3 - Evolução do cemitério entre 2010 e 2014.

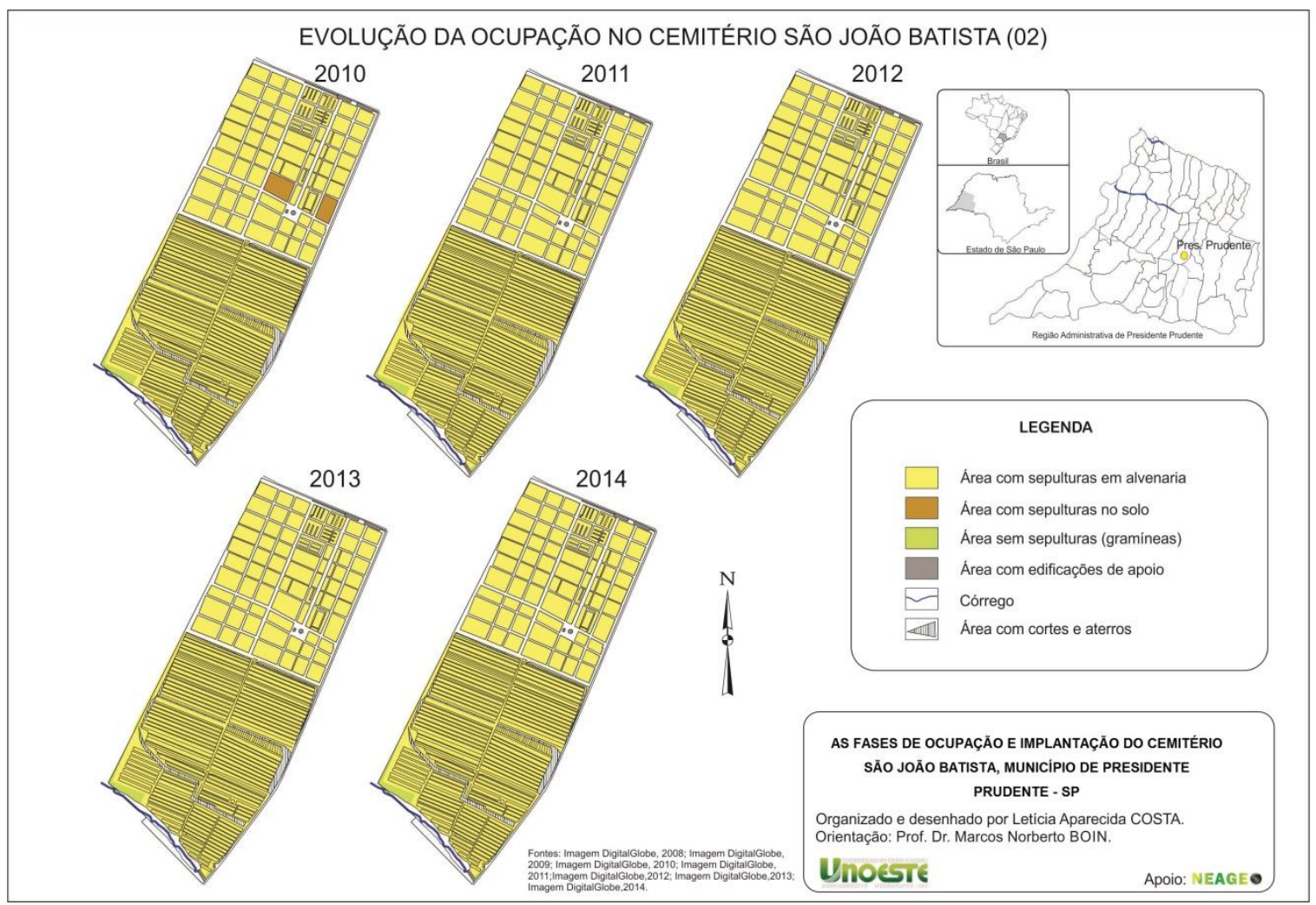

Fonte: COSTA, 2014.

Com o passar dos anos a área reservada para os sepultamento no solo foi sendo reduzida, e no ano de 2010 foi o ultimo ano em que se observaram quadras com sepultamento direto no solo, a partir de 2011 nenhuma área de solo foi destinada a receber sepultamento sem a construção de jazidos em alvenaria. A partir de então se reservou uma área para edificação de um columbário (túmulos verticais) para alocar os cadáveres de família que não possuíam condições financeiras para custear um jazigo.

Neste sentido o impacto dos cortes e aterros foi o de maior significância, pois representou um elevado número de cadáveres sepultados nas áreas de proximidade com o lençol freático. 
Assim o principal problema que adveio dos cortes é o afloramento do lençol freático, devido à profundidade que se realizou os cortes, impactando sobremaneira a qualidade da água subterrânea e consequentemente da água superficial. Outro aspecto de importância a ser considerado no que diz respeito à contaminação do freático foi à aproximação com o córrego Ferreirinha e o sepultamento sobre áreas de preservação permanentes.

A partir do ano de 2012 se começou a ocupar a área entre os túmulos, as áreas destinadas para a circulação dos visitantes, devido a grande demanda de corpos.

$\mathrm{Na}$ atual situação do cemitério São João Batista não existe espaço para novas aquisições de túmulos, sua atividade se restringe para aqueles que já possuem uma área.

\section{CONCLUSÃO}

Podemos considerar que a avaliação de impactos ambientais decorrentes da implantação e operação do cemitério é de extrema importância, visto que a sociedade necessita utilizá-lo e os levantamentos realizados demostraram que é necessário adequar e melhorar diversos fatores, como a forma e a área adequada para o sepultamento, para que a atividade se torne menos prejudicial ao meio ambiente e a sociedade em geral.

O cemitério São João Batista foi instalado e operado sem nenhum tipo de preocupação com o meio ambiente gerando diversos impactos e prejuízos.

A ocupação do cemitério ocorreu de maneira inadequada, sem qualquer tipo de planejamento, e conforme as necessidades de sepultamentos a ampliação foi sendo realizada, se estendendo por todo o terreno disponível. A ampliação só não foi maior, pois logo abaixo do cemitério se encontra o córrego Ferreirinha, mesmo assim muitos túmulos se localizam próximo a este córrego, estando dentro da área de preservação permanente.

Os recursos hídricos é um dos principais lesados, pois com a ampliação inadequada ocorre a percolação dos contaminantes da decomposição dos cadáveres. 
É de extrema importância projetar adequadamente os cemitérios, pois os sepultamentos acontecem de forma permanece, e os corpos precisam passar pelo processo de decomposição afetando o mínimo possível os recursos naturais.

\section{REFERÊNCIAS}

BRASIL. Ministério do Meio Ambiente. Resolução CONAMA n.ํ 335, de 3 de abril de 2003. Dispõe sobre Dispõe sobre o licenciamento ambiental de cemitérios. Conselho Nacional do Meio Ambiente.

BRASIL. Ministério do Meio Ambiente. Resolução CONAMA no 001, 23 de janeiro de 1986. Conselho Nacional do Meio Ambiente.

BRASIL. Ministério do Meio Ambiente. Resolução CONAMA no 396, 3 de abril de 2008. Dispõe sobre a classificação e diretrizes ambientais para o enquadramento das águas subterrâneas e dá outras providências. Conselho Nacional do Meio Ambiente.

CETESB. Norma Técnica - Implantação de Cemitérios. L1.040. São Paulo, 1999.

MIOTTO, S. L. Aspectos geológico-geotécnicos da determinação da adequabilidade de áreas para implantação de cemitérios. 1990. 116 f. 1990. Tese de Doutorado. Dissertação (Mestrado em Geociências)-Instituto de Geociências e Ciências Exatas, Universidade Estadual Paulista, Rio Claro.

MOTA, S. Introdução à Engenharia Ambiental. Rio de Janeiro: Expressão Gráfica, Rio de Janeiro, 2010.

OTTOMAN, F. (1987) Créer ou aménager un cimetière. Paris, Moniteur, 161p.

PACHECO, A., Meio Ambiente e Cemitérios, São Paulo: Editora Senac São Paulo, 2012.

PORTO, R.L.L.; Fundamentos para a Gestão da Água. São Paulo, 2012.

WORLD HEALTH ORGANIZATION - WHO. The impact of cemeteries on the envoirement and public health: an Introductory briefing. Copenhagen, Denmark: WHO Regional Office for Europe. 1998. $11 \mathrm{p}$. 